\section{An Image-based Method to Study the Fruit Tree Canopy and the Pruning Biomass Production in a Peach Orchard}

\author{
Joan Lordan \\ Departament de Medi Ambient i Ciències del Sòl, Universitat de Lleida, Av. \\ Rovira Roure 191, 25198 Lleida, Spain
}

\author{
Miquel Pascual \\ Departament d'Hortofruticultura, Botànica i Jardineria, Universitat de \\ Lleida, Av. Rovira Roure 191, 25198 Lleida, Spain
}

\section{Francisco Fonseca}

Departament de Medi Ambient i Ciències del Sòl, Universitat de Lleida, Av. Rovira Roure 191, 25198 Lleida, Spain

Víctor Montilla and Josep Papió

Departament de Medi Ambient i Ciències del Sòl, Universitat de Lleida, Av. Rovira Roure 191, 25198 Lleida, Spain

\section{Josep Rufat \\ Programa d'Ús Eficient de l'Aigua, Institut de Recerca $i$ Tecnologia Agroalimentàries (IRTA), Parc de Gardeny, Edificio Fruitcentre 25003 Lleida, Spain}

\section{Josep M. Villar ${ }^{1}$}

Departament de Medi Ambient i Ciències del Sòl, Universitat de Lleida, Av. Rovira Roure 191, 25198 Lleida, Spain

Additional index words. trunk diameter, digital photography, orthoimage canopy area, pruning weight, virtual pruning

\begin{abstract}
The feasibility of two nondestructive methods based on image processing techniques was assessed for fruit tree research. The methods were evaluated in a 2-year (2011 and 2012) field experiment, during which various irrigation and soil management treatments were set up in a commercial peach orchard. Canopy image analysis was conducted using two approaches, namely the orthoimage and the lateral image technique. The proposed methods were compared with other classical measurements such as trunk diameter (TD) increase and pruning weight (PW). Orthoimage canopy area (OCA) analysis resulted in a reliable and sensitive technique to study the active crop growth along the growing season. The OCA values obtained were highly correlated with TD measurements $\left(r^{2}=0.88\right)$, thus describing an exponential significant model $\left(y=0.0997 \mathrm{e}^{0.0521 x}\right)$. Cumulative crop growth was determined using the virtual pruning (VP) technique. VP estimates were well correlated with fruit tree PWs during $2011\left(r^{2}=0.86\right)$ and $2012\left(r^{2}=\right.$ 0.80). The nondestructive image-based techniques proved sensitive to crop growth and useful for the study of fruit tree canopies. On the basis of our results, we conclude that the proposed image analysis methods are valuable new approaches with wide applications in fruit tree research.
\end{abstract}

Tree canopy analysis has been widely studied. In this regard, Ross (1981) stated the importance of such analysis to further our

\footnotetext{
Received for publication 9 July 2015. Accepted for publication 25 Oct. 2015.

Joan Lordan received an FI grant from the Agency for Management of University and Research Grants (AGAUR) of the Government of Catalonia. This research was financed by the project grant RTA2009-00056-00-00 from Spain's Ministry of Economy and Competitiveness.

${ }^{1}$ Corresponding author. E-mail jmvillar@macs.udl.cat.
}

the interception of solar radiation (Loomis et al., 1967; Monteith, 1969). Thus, by studying canopy area, it is possible to evaluate the response of plants to environmental conditions or crop management strategies, e.g., irrigation, fertilization, and soil management (Ali and Anjum, 2004).

The quantification of biomass production in multiannual crop experiments is a challenge since most classical methods are destructive and/or involve laborious assessments. Plant and leaf sampling is an accurate method for this purpose (Evans, 1972), but it is not suitable when measurements are repeated periodically. In these cases, it is appropriate to apply allometric models that relate shape and size of the leaves to the leaf area, which can be defined with great precision. In contrast, these models involve tedious measurements that require long-term sampling, especially during periods of active growth when shape and size of the leaves change rapidly (Baker et al., 1996).

Other common methods to determine fruit tree growth and development include the measurement of TD and shoot length; however, these two approaches provide only a rough idea of total biomass, and their relationships with total crop growth is influenced by many factors, such as plant competition, fructification, and cultural interventions (Bevacqua at al., 2012; Willaume et al., 2004) Pruning weight is another common method for biomass production study; however, it provides information only on cumulative tree growth and it is not suitable for the analysis of crop development at distinct phenological stages. Other techniques based on the measurement of interception and transmission of solar radiation in leaf canopies (Jonckheere et al., 2004) can be used to evaluate the development of the canopy but lack precision (Bréda, 2003). The most common method to determine the LAI is based on the measurement of photosynthetically active radiation $(P A R)$ both above and below the canopy (Board et al., 1992).This method involves several $P A R$ measurements taken using sensors placed beneath the canopy. However, as an indirect method to estimate the LAI, it requires several measurements to characterize the crop canopy.

Over the last 25 years, precision agriculture has been introduced in many areas of the world along with the arrival of remote sensors mounted in satellites, aerial vehicles, or tractors (Mulla, 2013). Among them, light detection and ranging (LiDAR) technology has arisen as a precise tool to estimate the canopy volume of fruit trees (Pallejà et al., 2010). Although this technology is still very expensive, it is likely to be adopted in the coming years as the price of the sensors decrease.

During recent decades, traditional photography has evolved to digital photography, leading to the development of a full range of electronic light sensors. Although digital technology was initially costly, it is now highly affordable.

Digital camera sensors convert light into digital information, which can then be modified, treated, and analyzed by computer programs. With the availability of digital light 
sensors, there are now viable alternatives for estimating growth and biomass production in many crops. Digital image analysis has been reported to be a precise method to quantify crop biomass production (Campillo et al., 2011, 2008; Pforte et al., 2012; Rico-García et al., 2009; Serdar and Demirsoy, 2006). Earlier studies (Diebolt and Mudge, 1988; Lindsey and Bassuk, 1992) found a close relationship between the LAI and image measurements, thus providing additional benefits over traditional methods (Smith et al., 1991). However, the cited studies (Diebolt and Mudge, 1988; Lindsey and Bassuk, 1992) were carried out before the digital photography era and the developed systems required many additional systems (i.e., photography cameras, video cameras, negative films, monitors, etc.) that limited the expansion of the methodologies across the research community. Nowadays, the advances in digital photography and computing software ease the expansion of new proposed alternatives, as the ones proposed in this article.

Image-based techniques offer a full range of applications for implementation in fruit tree science, where other methods either lack consistency or are not feasible. In this work we evaluated the use of digital image analysis to study the crop canopy and crop growth in a commercial peach orchard under different irrigation and soil management treatments. The objective was to assess the feasibility of image analysis techniques through digital photography as a supplementary tool for crop response assessment and crop biomass estimation.

\section{Material and Methods}

Experimental site and applied treatment. The experiment was conducted during 2011 and 2012 in a commercial peach orchard located in Los Monegros region (Huesca, Spain). The climate is semiarid Mediterranean, with an annual rainfall of $350 \mathrm{~mm}$. Trees were planted in 2011 in a ridge planting system. One-year-old peach trees [Prunus persica (L.) Batsch cv. Saturn] grafted onto GF-677 were grown with a spacing of $5 \mathrm{~m} \times$ $2.5 \mathrm{~m}$. Soil texture is loam $(40.3 \%$ sand, $39.8 \%$ silt, and $19.9 \%$ clay) (U.S. Department of Agriculture classification). A randomized complete block design with three replications was set up. Each elementary plot contained seven trees. Plant measurements were made on the five central trees. Six different soil and water management treatments were evaluated (Table 1): ridge planting with drip irrigation at $100 \%$ of the calculated irrigation requirement (R-DI-100); ridge planting with drip irrigation at $70 \%$ of the calculated irrigation requirement (R-DI-70); ridge planting with subsurface drip irrigation at $100 \%$ of the calculated irrigation requirement (R-SDI-100); ridge planting with subsurface drip irrigation at $70 \%$ of the calculated irrigation requirement (R-SDI-70); ridge planting with subsurface drip irrigation at $70 \%$ of the calculated irrigation requirement and air injection through the irrigation system (RSDI-70 + AIR); and modified ridge planting with subsurface drip irrigation at $70 \%$ of the calculated irrigation requirement (MR-SDI70). The irrigation water requirement was calculated using the methodology proposed by the Food and Agriculture Organization of the United Nations (Allen et al., 1998). Air injection was performed with a venturi air injector (MAI-A3, Toro Ag Irrigation, El Cajon, CA). The modified ridge treatment included substrate taken from around the dripperline, which included a mix of soil, rice husk, and gypsum, at respective proportions of 12:12:1. Ridge dimensions were $1.5 \mathrm{~m}$ (bottom) and $1 \mathrm{~m}$ (top) wide and $0.8 \mathrm{~m}$ high. In subsurface irrigation treatments, the dripperline was buried between $0.25 \mathrm{~m}$ and

Table 1. Irrigation and soil management treatments applied in the experimental plot.

\begin{tabular}{lllll}
\hline Treatment & \multicolumn{1}{c}{ Ridge type } & \multicolumn{1}{c}{ Drip system } & Irrigation dose & Air injection \\
\hline R-DI-100 & Normal ridge & Surface drip irrigation & $100 \%$ & - \\
R-DI-70 & Normal ridge & Surface drip irrigation & $70 \%$ & - \\
R-SDI-100 & Normal ridge & Subsurface drip irrigation & $100 \%$ & - \\
R-SDI-70 & Normal ridge & Subsurface drip irrigation & $70 \%$ & $12 \%$ Air injection (by volume) \\
R-SDI-70 + AIR & Normal ridge & Subsurface drip irrigation & $70 \%$ & - \\
MR-SDI-70 & Ridge modified with rice husk substrate & Subsurface drip irrigation & $70 \%$ & - \\
\hline
\end{tabular}



Fig. 1. Layout of the method used in the (A) orthoimage technique and (B) lateral technique. 
$0.3 \mathrm{~m}$ below the surface and was placed at a distance of between $0.15 \mathrm{~m}$ and $0.2 \mathrm{~m}$ from each tree trunk.

Measurements. Crop growth was analyzed through canopy image analysis, TD, and PW for five control trees per plot during the 2011 and 2012 growing seasons. Canopy image analysis was conducted by using two approaches: the orthoimage technique and the lateral image technique. The orthoimage technique was used to study evolution of the canopy foliage during active tree growth (canopy with leaves), whereas the lateral image technique was used to study the cumulative shoot/branch growth between growing seasons (canopy without leaves). In the orthoimage technique, the photographs were taken using a digital single-lens reflex camera (D5100, Nikon, Japan) with a wideangle zoom lens (SP AF 10-24 mm F/3.5-4.5 Di II LD Aspherical IF; Tamron, Japan) placed in a gyroscope on the top of an arch placed at a height of $3.5 \mathrm{~m}$ as shown in Fig. 1A. The photographs were transferred to a computer and processed using commercial software (Photoshop CS5; Adobe Systems, San Jose, CA) to isolate the green pixels of the canopy. Images were processed to grayscale images (8-bit) to calculate the image area (IA) that corresponded to the isolated black canopy area by using open source software (ImageJ, National Institutes of Health, Bethesda, MD). The grayscale cutoff point was set up manually for $5 \%$ of the images (randomly selected) to select all the canopy pixels. Once the threshold was selected, it was applied for the rest of the images of the same batch (same date). This action of the process required the expertise of an image technician to include all the pixels of the canopy in the pixel counting. An OCA value was obtained for each tree measurement by applying the following equation:

$$
\mathrm{OCA}=\frac{\mathrm{IA}}{\mathrm{S}^{2}}
$$

where OCA is measured in $\mathrm{m}^{2}$, IA is measured in pixels, and $\mathrm{S}$ is the previously calculated image scale measured in pixel $/ \mathrm{m}$. The image scale $(\mathrm{S})$ depends on the distance between the studied object and the lens camera. A reference object with known dimensions was placed before to establish a fixed image scale (S), which was maintained constant through the whole measurement, since the object-lens distance was maintained constant (same arch height).

The increase in OCA was also determined by applying the following equation:

$$
\Delta \mathrm{OCA}_{(\text {year })}=\mathrm{OCA}_{(\mathrm{n}, \text { year })}-\mathrm{OCA}_{(1, \text { year })}
$$

where $\triangle \mathrm{OCA}$ is the season increase in the $\mathrm{OCA}$ in $\mathrm{m}^{2}$ during the growing season, $\mathrm{OCA}_{\mathrm{n}}$

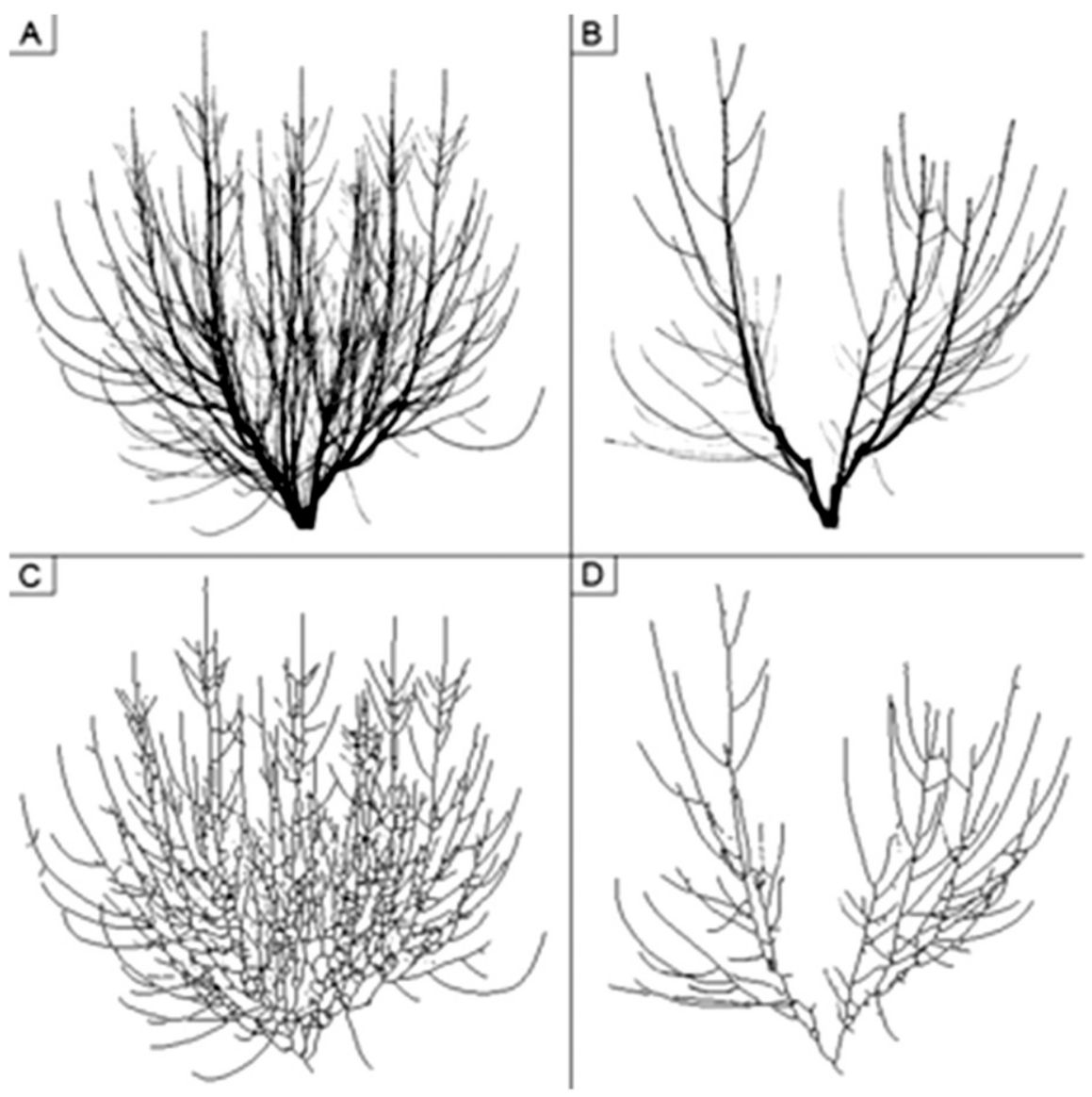

Fig. 2. Isolated area of the canopy (A) before pruning and (B) after pruning. Skeletonized images used to calculate the total length $(\mathbf{C})$ before pruning and (D) after pruning. is the last OCA measurement of the season in $\mathrm{m}^{2}$, and $\mathrm{OCA}_{1}$ is the first OCA measurement of the season in $\mathrm{m}^{2}$.

In the lateral image technique, the photographs were taken using a digital single-lens reflex camera (D5100) with wide-angle zoom lens (SP AF 10-24 mm F/3.5-4.5 Di II LD Aspherical IF) placed on a monopod at a height of $1.5 \mathrm{~m}$ as shown in Fig. 1B. One picture per tree was taken at a distance of $\approx 4 \mathrm{~m}$. A white net was placed behind the tree canopy to increase the canopy contrast and ease the brown pixels isolation by computer means. The photographs were transferred to a computer and processed using specific software (Photoshop CS5) to isolate the brown pixels of the canopy and thus obtain a simpler image, which was finally processed to a grayscale image (8-bit) using ImageJ software. This image was then converted to binary by defining a grayscale cutoff point and then skeletonized (reduced to single pixel lines) using Image J software to measure its total length (TL) (in pixels) (Fig. 2). The grayscale cutoff point was determined for $5 \%$ of the images (which were randomly selected) and then applied for the rest of the images of the same batch (same date). Image scale ( $S$, in pixels $/ \mathrm{m}$ ) was obtained using ImageJ and a reference object with known dimensions, which appeared in every photograph. Using this technique, it was possible to calculate two variables, namely VP and cumulative shoot growth (CSG), as defined by the following equations:

$$
\mathrm{VP}_{\text {year }}=\mathrm{TL}_{\text {bp year }}-\mathrm{TL}_{\text {ap year }}
$$

where $\mathrm{VP}_{\text {year }}$ is the $\mathrm{VP}$ in $\mathrm{m} /$ tree, $\mathrm{TL}_{\mathrm{bp}}$ is the total canopy length in $\mathrm{m} /$ tree before pruning, and $\mathrm{TL}_{\text {ap }}$ is the total canopy length in $\mathrm{m} /$ tree after pruning.

$$
\mathrm{TL}=\frac{\mathrm{TL}_{\mathrm{px}}}{\mathrm{S}}
$$

where TL is the total canopy length in $\mathrm{m} /$ tree, $\mathrm{TL}_{\mathrm{px}}$ is the total canopy length in pixels/tree, and $\mathrm{S}$ is the calculated image scale in pixels $/ \mathrm{m}$.

$$
\mathrm{CSG}_{\text {year }}=\mathrm{TL}_{\text {bp year }}-\mathrm{TL}_{\text {ap year-1 }}
$$

where $\mathrm{CSG}_{\text {year }}$ is the $\mathrm{CSG}$ in $\mathrm{m} /$ tree, $\mathrm{TL}_{\mathrm{bp} \text { year }}$ is the total canopy length in $\mathrm{m} /$ tree before pruning, and $\mathrm{TL}_{\mathrm{ap}}$ year-1 is the total canopy length in $\mathrm{m} /$ tree after pruning the previous year.

Trunk diameter measurements were carried out using a digital caliper (Digimatic; Mitutoyo America Corporation, Chicago, IL) placed $0.1 \mathrm{~m}$ above the soil. Trees were dormant when pruned in the winters of 2011 and 2012, and PW (in kg/tree) was determined in five control trees per plot.

A repeated-measures multivariate analysis of variance was used to analyze TD and OCA evolution over time. A linear mixed model (Type III sum of squares) for the analysis of estimated marginal means was built to separate treatment effects for PW and VP variables. Tukey's honestly significant difference (THSD) post hoc test was used to compare treatments regarding pruning data. 


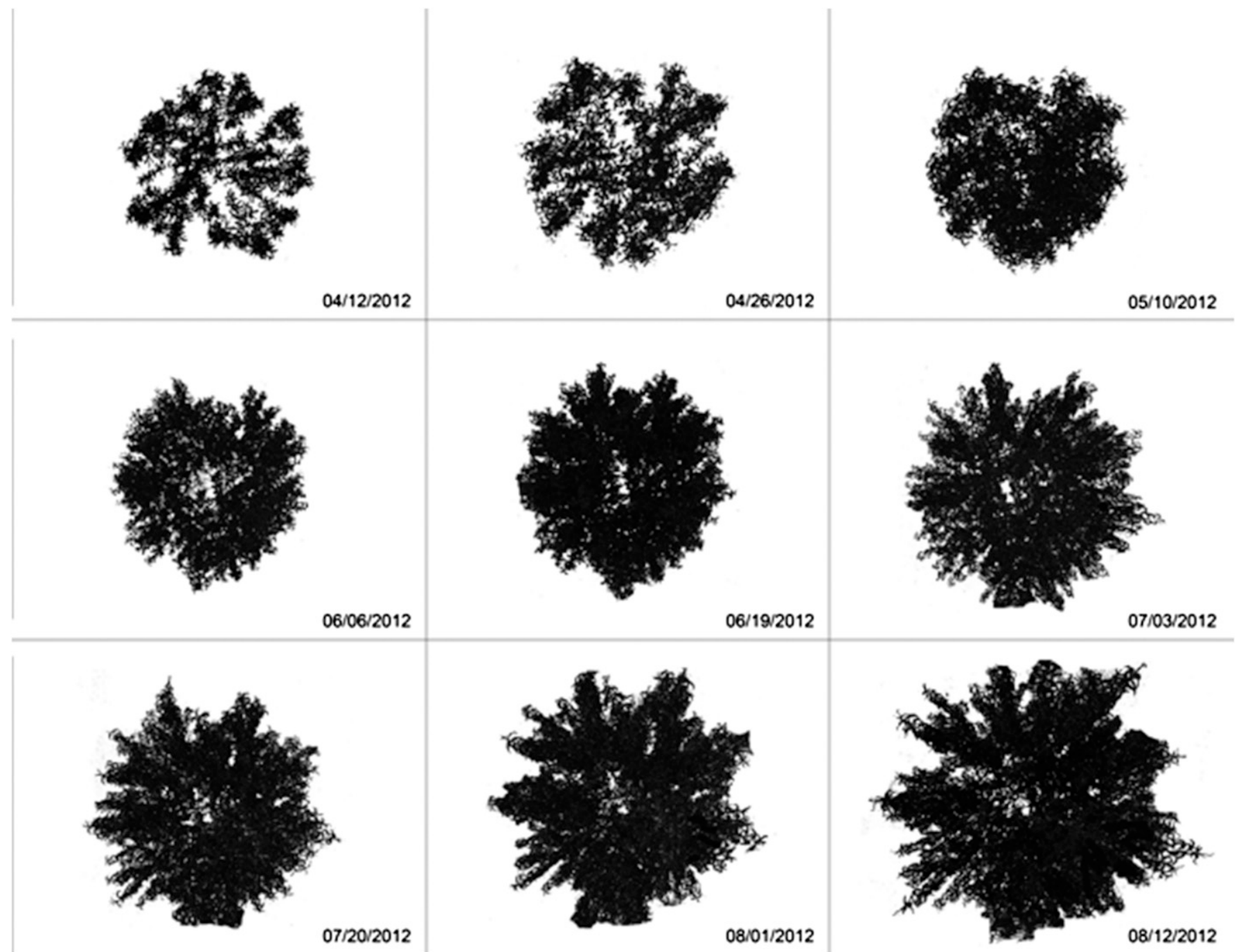

Fig. 3. Canopy growth evolution of a tree canopy throughout the 2012 growing season obtained by using the orthoimage technique.

A probability level of $P<0.05$ was used for all statistical analyses.

\section{Results and Discussion}

Study of the active crop growth. An example of the evolution of the tree canopy growth (orthoimage canopy) is shown in Fig. 3. Figure 4 shows the evolution of TD for different treatments along the 2012 growing season with values ranging from $35.2 \mathrm{~mm}$ (R+DI-70 in 19 Jan. 2012) to $76.6 \mathrm{~mm}$ (MR+SDI-70, in1 Aug. 2012). We observed significant differences between treatments $(P<0.0001)$ and also found that the time at which the images were taken significantly affected the measurement $(P<$ $0.0001)$. The interaction between treatment and time was also significant $(P<0.0001)$, suggesting that some treatments showed a different behavior over time compared with others. Figure 5 shows the evolution of OCA for the treatments in 2012 growing season with values ranging from $0.34 \mathrm{~m}^{2}$ (R-DI-70, in12 Apr. 2012) to $7.03 \mathrm{~m}^{2}$ (MRSDI-70, in 12 Aug. 2012). We observed significant differences between treatments
$(P<0.0001)$, as well as a time effect $(P<$ $0.0001)$. The interaction between treatment and time for this variable was found to be significant $(P<0.0001)$.

Both TD and OCA were good treatment descriptors as both were found to be highly significant $(P<0.0001)$ during 2012 . However, it is important to compare the overall treatment trend in both figures, as the objective was to evaluate the OCA variable as an indicator of fruit tree growth. Both TD and OCA showed similarities regarding treatment evolution along the season. While the MR+SDI-70 treatment registered the highest levels for the TD and the OCA data, the $\mathrm{R}+\mathrm{SDI}-70$ treatment gave the lowest values for these two variables.

The relationship between TD and OCA variables is shown in Fig. 6. A model was constructed using 540 observations from several measurements along the season. The exponential curve fitting was the most suitable method to describe the allometric model between the two variables. The model $(y=$ $\left.0.0997 \mathrm{e}^{0.0521 x}\right)$ was significant $(P<0.0001)$ and showed a high coefficient of determination $\left(r^{2}=0.8797\right)$. Exponential models are commonly observed in allometric studies where total tree biomass is related to TD (Ahmed et al., 2013; Durkaya et al., 2013). However, such studies were conducted in forestry science experiments for uncultivated species, which were not altered, e.g., pruning, thinning. Our experiment was conducted in a commercial tree orchard subjected to crop maintenance practices, such as pruning, fertilization, and irrigation, during the growing season. Cultural practices may disrupt the relationship between the trunk and the canopy, especially those directly affecting the canopy/trunk of the tree, e.g., pruning.

The most notable trend in Fig. 6 is the large uncertainty of canopy area estimates for larger TD. While canopy area was easily estimated during the early crop stages (lower TD), the relationship between the variables became uncertain at late crop stages (greater TD). In addition, this relationship could have described different models depending on the tree species, the training system, or even the crop maturity, and thus it should be important to study and validate this approach on different scenarios.

TD and OCA both proved to be useful in the measurement of fruit tree growth, 


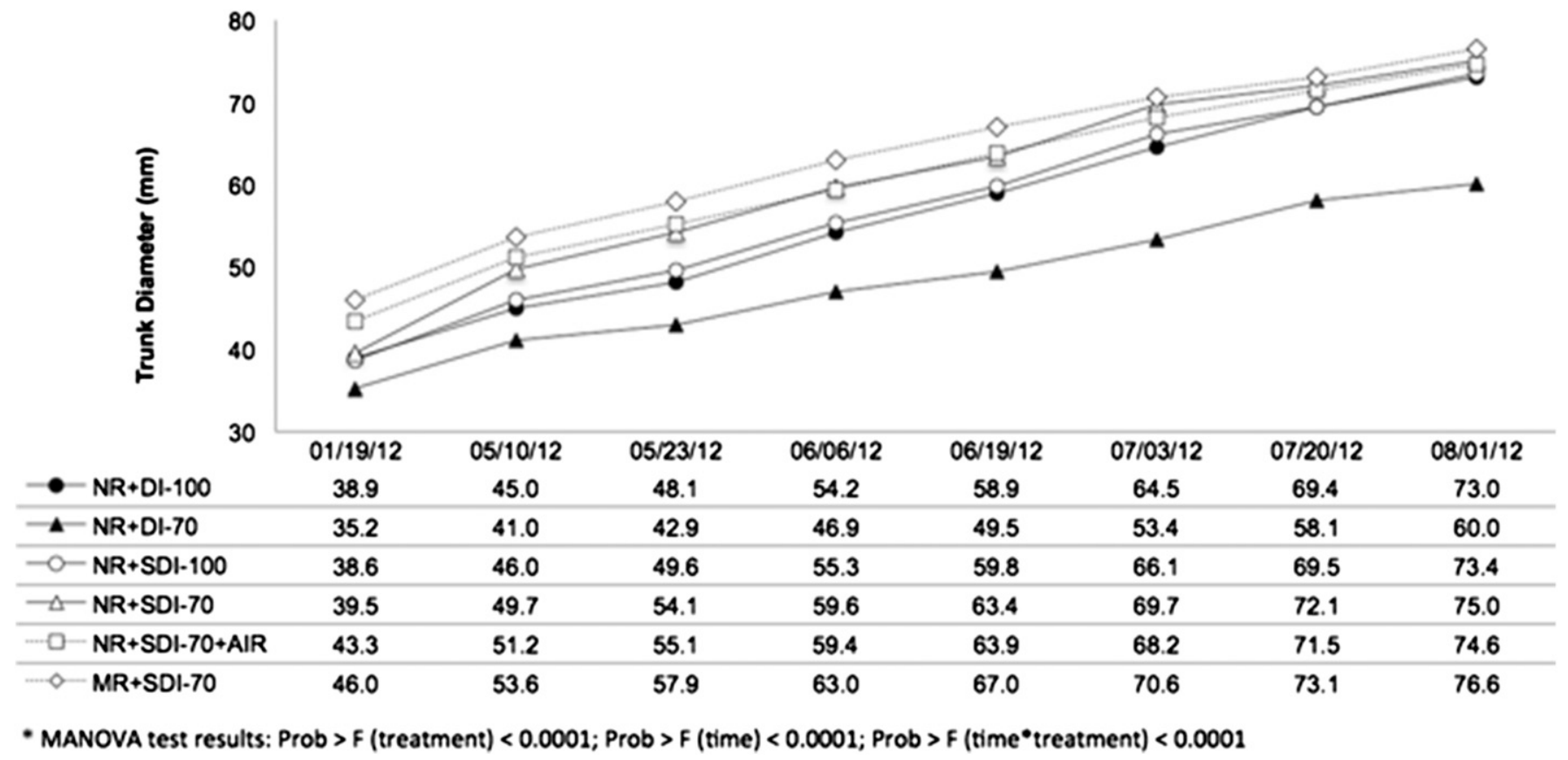

Fig. 4. Trunk diameter evolution during the 2012 growing season for the different treatments. Expressed values are the calculated treatment means for the selected dates ( $x$-axis).

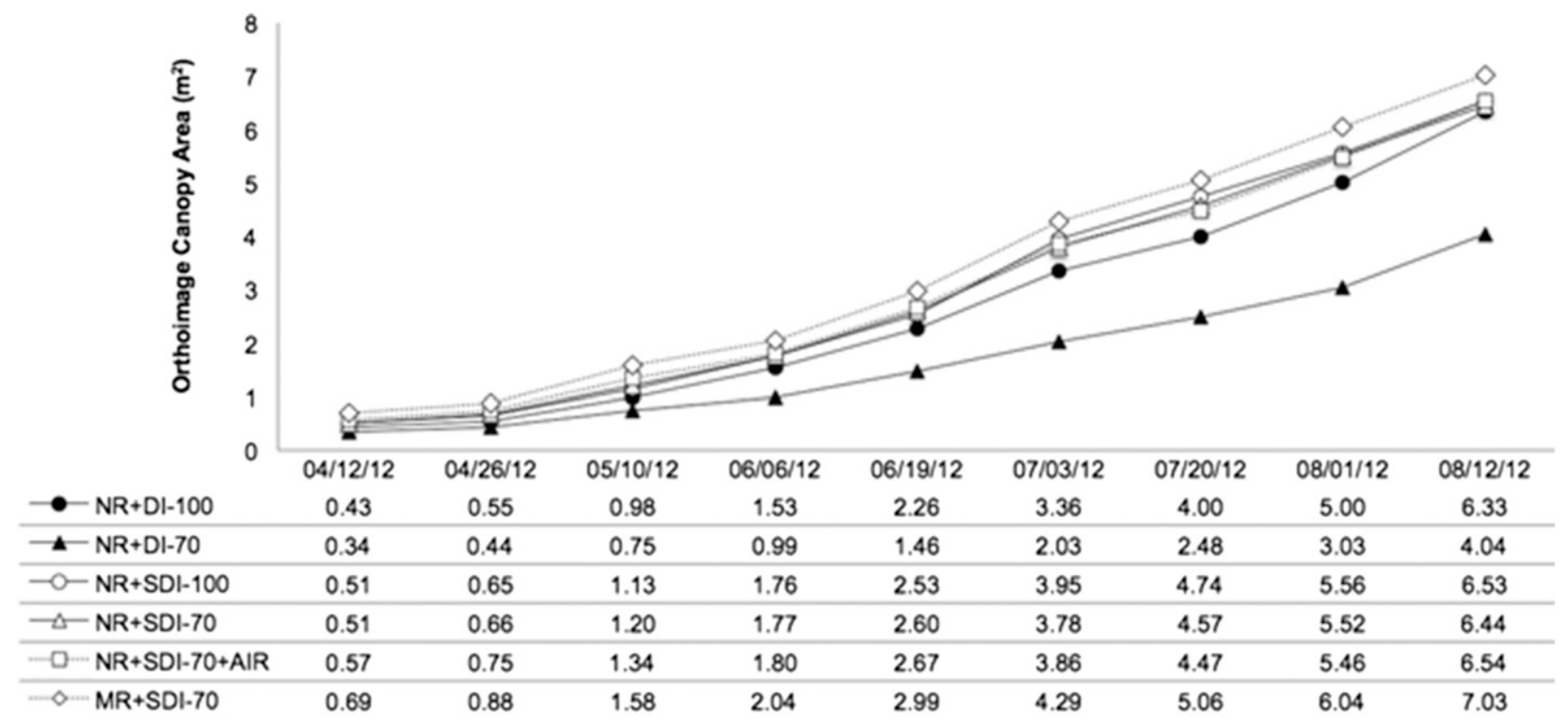

- MANOVA test results: Prob $>F$ (treatment) $<0.0001 ;$ Prob $>F$ (time) $<0.0001$; Prob $>F$ (time*treatment) $<0.0001$

Fig. 5. Orthoimage canopy area evolution during the 2012 growing season for the different treatments. Expressed values are the calculated treatment means for the selected dates ( $x$-axis).

although they provide information on distinct tree parameters. Although TD measurements are cumulative between seasons, OCA measurements are cyclic, since leaf biomass is produced and destroyed every season. Continuous measurement of canopy area provides important information on crop growth, which can be used in understanding crop performance under different cultural strategies. For instance, Fernández-Pacheco et al. (2014) applied image-based methods to estimate crop coefficient $\left(\mathrm{K}_{\mathrm{c}}\right)$ values in horticultural crops. Canopy volume of fruit trees can be well estimated by using LiDAR sensors, as reported in many studies (Palacín et al., 2007; Pallejà et al., 2010; Wei and Salyani, 2005). However, the price of these sensors is still high so image techniques based on digital photography have been lately introduced in agricultural research. For instance, Pforte et al. (2012) found that two-dimensional canopy images obtained by digital cameras were well correlated with those obtained by LiDAR sensors, suggesting that digital cameras could be used as precise tools to estimate canopy areas. The introduced methodology was used to evaluate the differential response in canopy growth among treatments rather than to estimate the real tree biomass. Thus, the proposed methodology must be precise but no 
necessarily accurate, since its purpose is to compare the vegetative response of the trees among treatments. There exist other techniques to estimate vegetative biomass such as satellite imagery, which is mainly used to map the biomass of forests across large regions of the globe (Berner et al., 2015; Le Toan et al., 2011). In crop science, this technology is commonly used to construct crop production models (Goetz et al., 1999) or to estimate large agricultural crop areas (Gallego et al., 2014). However, satellites resolution $(\approx 20$ or $30 \mathrm{~m}$ per pixel) represents a challenge to study small differences between tree canopies such as the ones presented in this article. As image resolution increases and other sensors are implemented in satellites, this methodology will certainly evolve as a useful tool for remote sensing for agricultural crops. Meanwhile, there exist other nondestructive methodologies to measure canopy growth and development that uses hemispherical lens, e.g., LAI-2000 or HEMIPHOTO, which have been widely used to study forest structures. However, they require many assumptions, such as a uniform canopy, which may not always be satisfied (Li et al., 2014).

The resources applied to determine the TD and OCA differed considerably. Each measurement required the acquisition of the TD and the OCA of 96 trees (entire plot). It

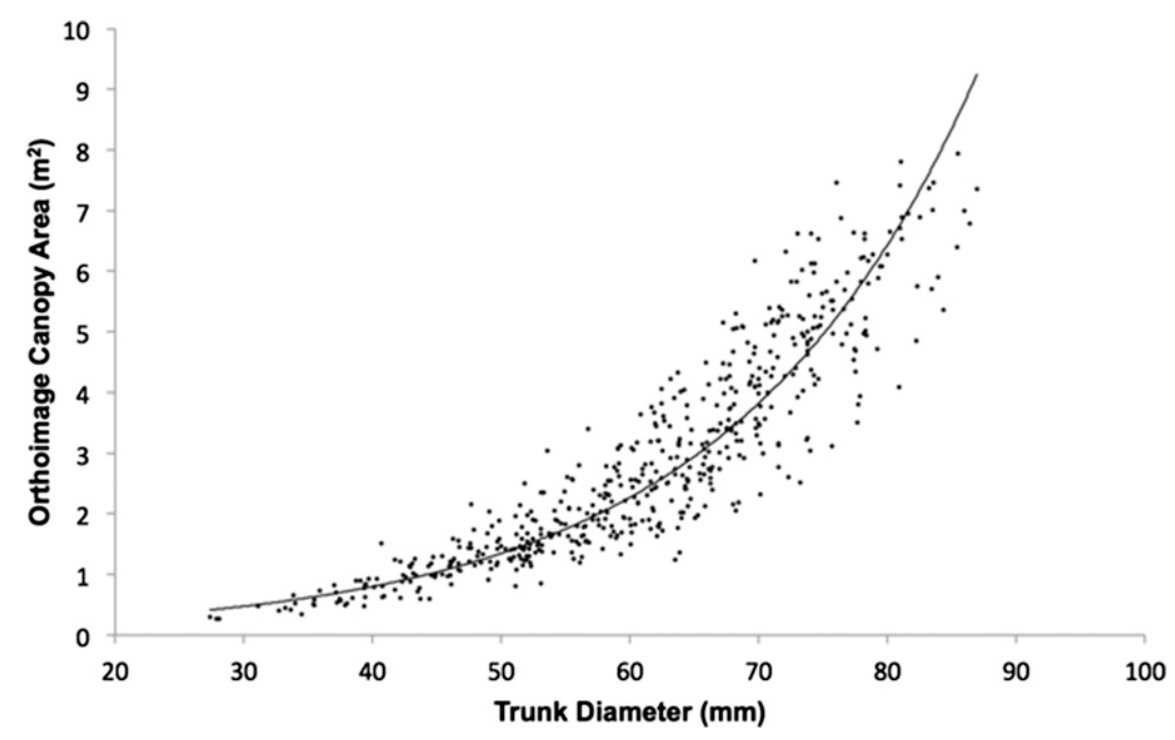

Fig. 6. Correlation between orthoimage canopy area and trunk diameter. Curve fitting equation: $y=0.0997 \mathrm{e}^{0.0521 \times} . P($ model $)<0.0001 . r^{2}: 0.87967$. took two people $1 \mathrm{~h}$ to measure the TD of the entire plot (equivalent to 2.0 man-hours). On the other hand, it took three people $30 \mathrm{~min}$ to take the photographs for the OCA measurement. In addition, the OCA measurement took one person $1 \mathrm{~h}$ to process all the images by computer and to obtain the OCA values (equivalent to 2.5 man-hours). The camera was mounted at $3.5 \mathrm{~m}$ at the top of an arch and required three people to perform each OCA measurement. During the last year we developed a jib trolley to mount the digital camera on which allowed to perform the same process by consuming less resources since the measurement could be executed by a single operator within the same period of time (30 min per 96 trees). In this sense, the development of new image sensors with higher resolutions, such as LiDAR sensors, along with the arrival of new technology, such as the unmanned aerial vehicle drones, might suppose a remarkable advance in image techniques and fruit tree research. Until then, image analysis via digital photography techniques is presented as a low-cost tool that provides reliable and fast information on crop response. It was necessary to perform the OCA measurements in certain meteorological conditions to obtain highquality canopy images. For that purpose the photographs were taken in cloudless conditions so that the illumination and the canopy colors were standardized during the measurements. It was necessary as well, to avoid the measurements in windy conditions so that the canopy shape was unaffected during the image process.

Study of the cumulative crop growth. Pruning weight, expressed as $\mathrm{kg} / \mathrm{tree}$, has been widely used in fruit tree research as a classical method to evaluate crop growth under different management strategies

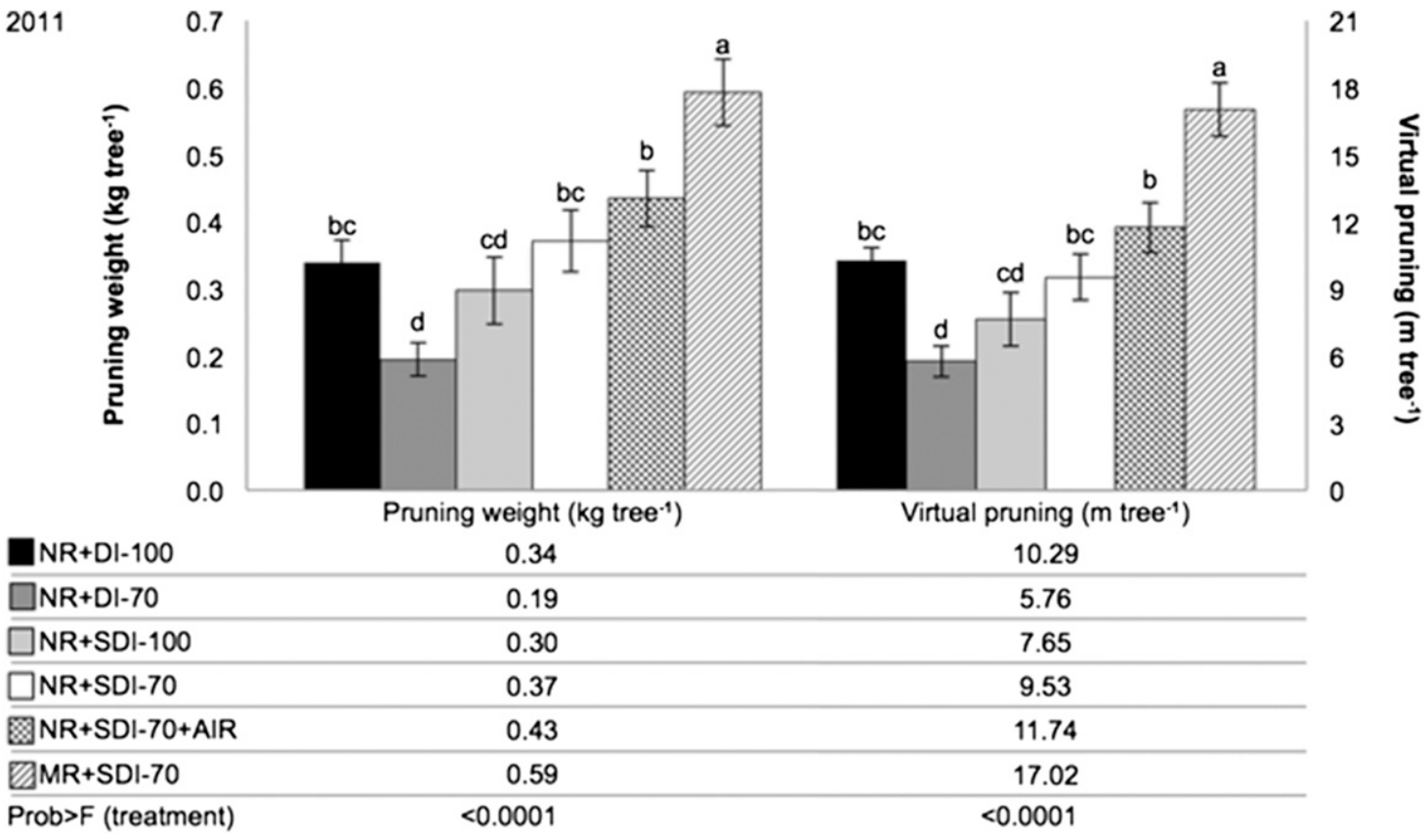

Fig. 7. Pruning weight ( $\mathrm{kg} /$ tree) mean and virtual pruning $(\mathrm{m} / \mathrm{tree})$ mean values for the different treatments for the 2011 growing season. 


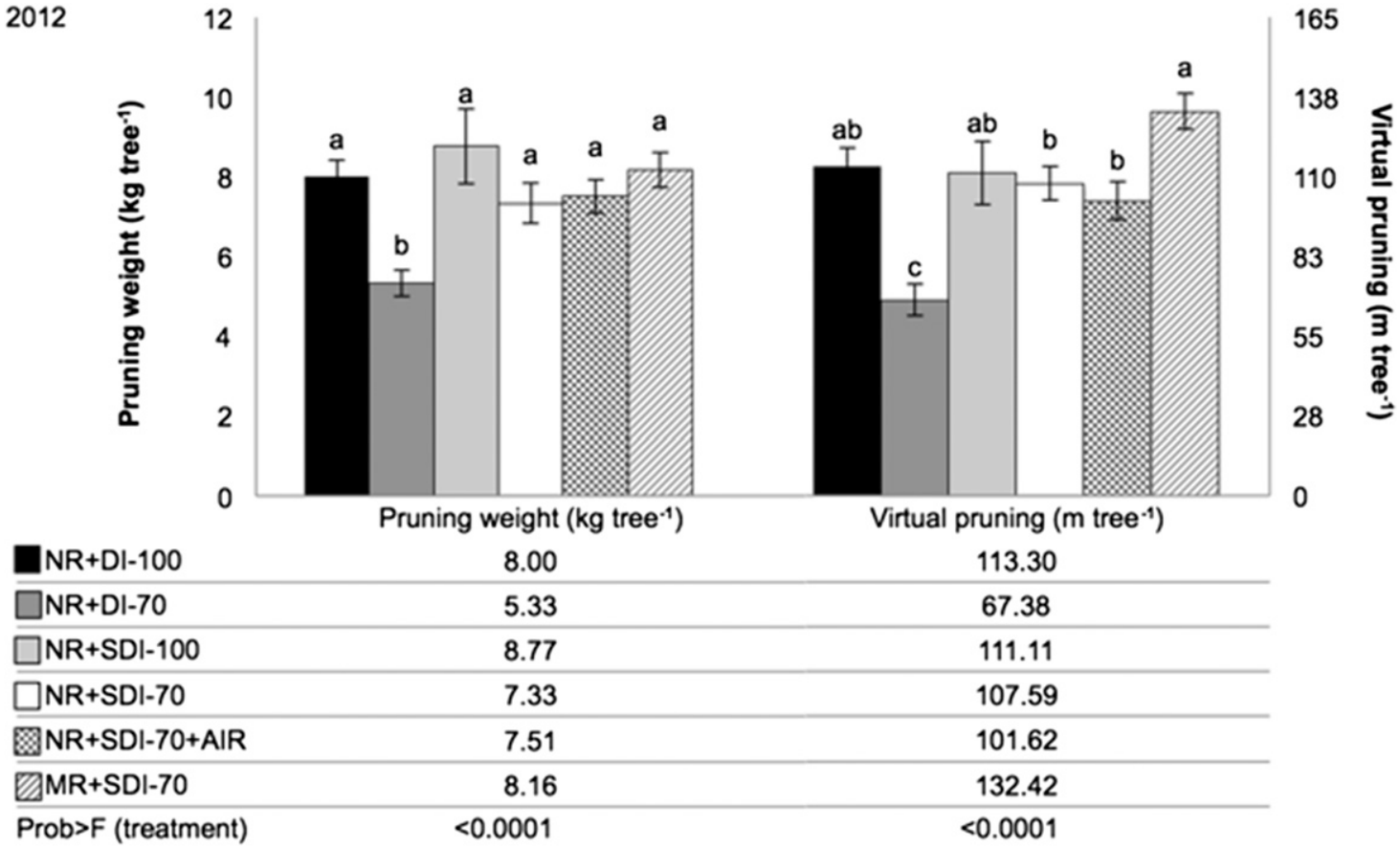

Fig. 8. Pruning weight $(\mathrm{kg} / \mathrm{tree})$ mean and virtual pruning $(\mathrm{m} / \mathrm{tree})$ mean values for the different treatments for the 2012 growing season.

(Abrisqueta et al., 2010; Bryla et al., 2003, 2005). However, this technique is highly time consuming and requires many operators to carry out the measurements when performed in crops with high pruning requirements. Figures 7 and 8 show the mean distribution of PW (in $\mathrm{kg} /$ tree) and VP (in $\mathrm{m} /$ tree) measurements for the different treatments in 2011 and 2012, respectively.

The effects of the treatments were significant in both years $(P<0.0001)$, with similar treatment distributions. In 2011, PW and VP reflected the same differences between treatments, as they had exactly the same factor level means as shown by test. In 2012, the distribution was quite similar between variables, although VP was more sensitive, as reflected by more factor level means in THSD test. Figure 9 shows the correlation between PW and VP in 2011 and 2012. The correlation between these two variables can be described by a significant linear model $(P<$ $0.0001)$, which presented a high correlation index $\left(r_{2011}^{2}=0.86 ; r_{2012}^{2}=0.80\right)$. Thus, there was a close relationship between PW and VP. On the basis of this observation, we propose that it is possible to determine cumulative tree growth by applying VP method. However, the relationship between these variables could vary over time. As trees grow the branches suffer from overlapping and the VP could underestimate the real pruning biomass (as seen in Fig. 9 in 2012). Of course, the correlation between PW and VP could also depend on the training system (flat vs. vase-shaped training systems), so the model should be validated in different training and pruning systems.

The resources applied to determine PW and VP differed considerably. It took three people $4 \mathrm{~h}$ to measure the $\mathrm{PW}$ of the entire
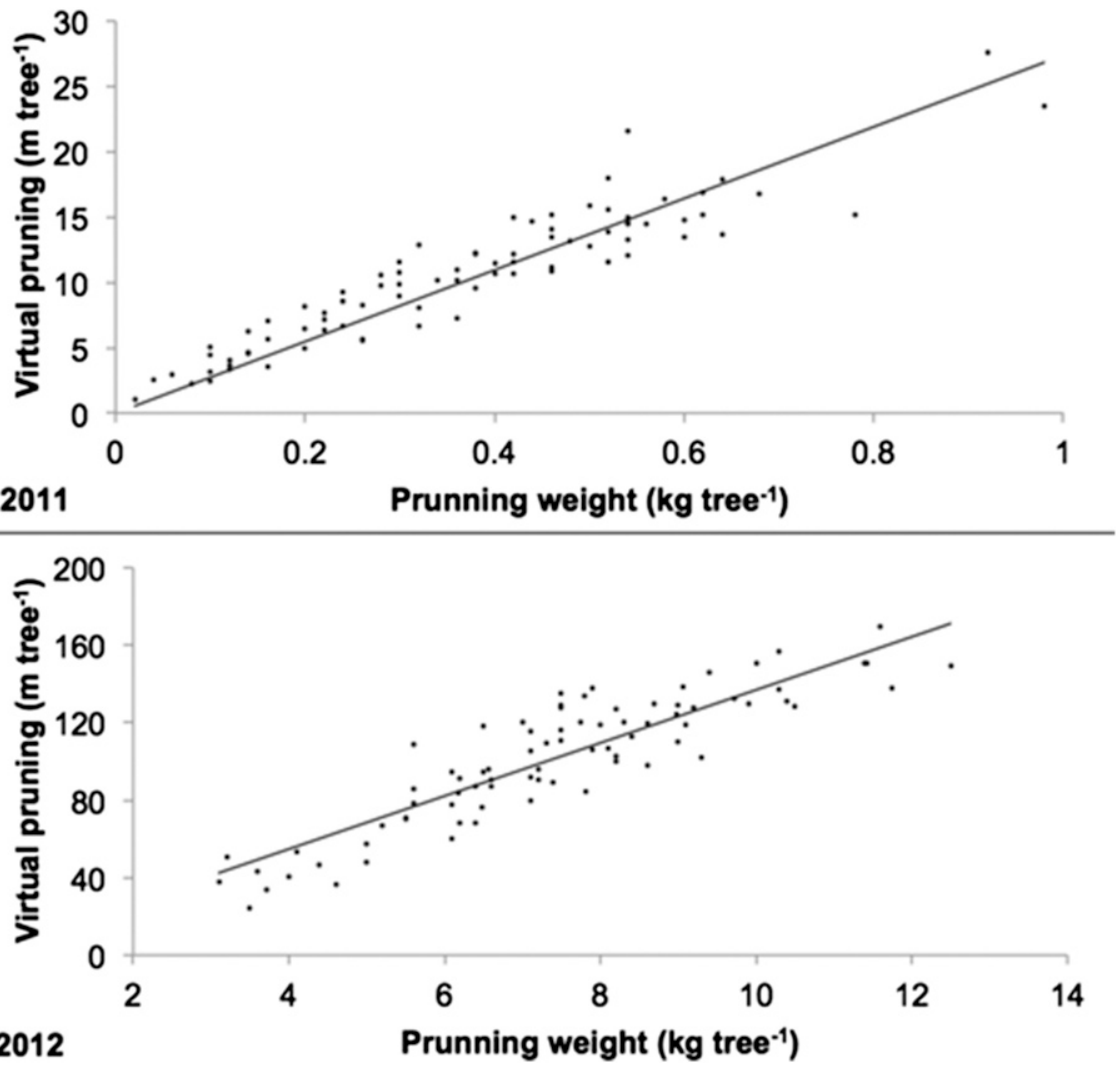

Fig. 9. Virtual pruning and pruning weight correlation in 2011 (upper image) and 2012 (lower image) growing seasons. $P$ (model) in $2011<0.0001 . r^{2} 2011: 0.86107 . P$ (model) in $2012<0.0001 . r^{2}$ in 2012 : 0.80393 .

plot (equivalent to 12.0 man-hours). On the other hand, it took three people $30 \mathrm{~min}$ to take the photographs needed for the VP measurement (96 trees). In addition, the VP measurement took one person $30 \mathrm{~min}$ to process all the images by computer and to obtain the VP values (equivalent to 2.0 manhours). The VP methodology required fewer resources (2.0 vs. 12.0 man-hours) and provided more information about the orchard 


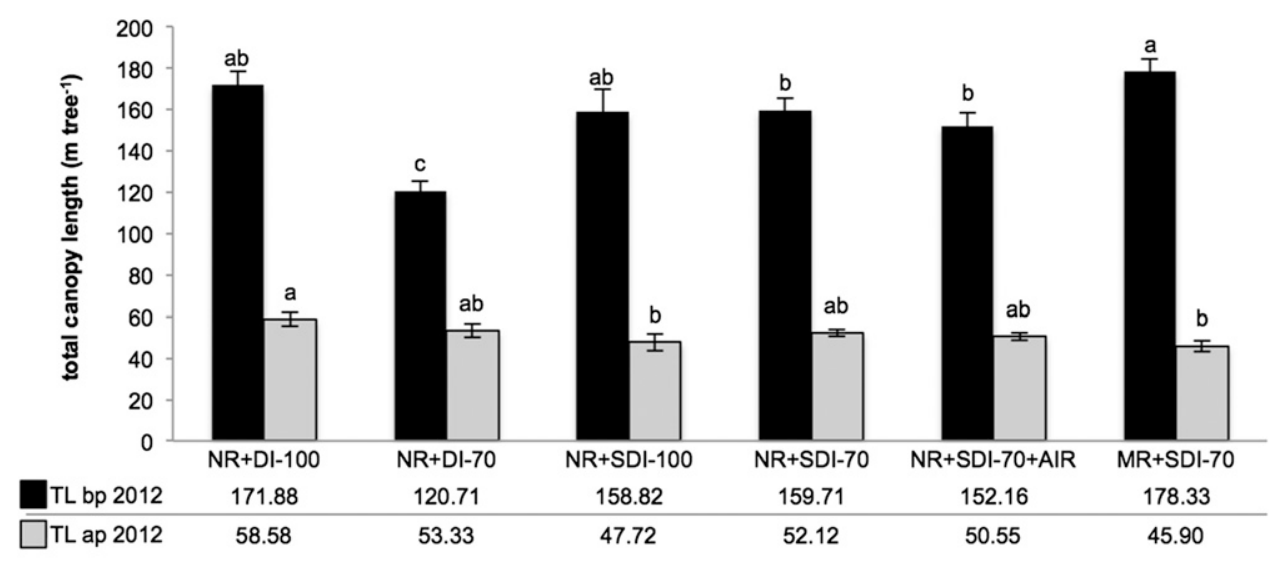

* Prob>F TL bp 2012 (treatment) $<0.0001-$ Prob $>$ F TL ap 2012 (treatment) $=0.0257$

Fig. 10. Treatment mean values for total canopy length before $\left(\mathrm{TL}_{\mathrm{bp} \mathrm{2012}}\right)$ and after $\left(\mathrm{TL}_{\mathrm{ap} \mathrm{2012}}\right)$ pruning in the 2012 growing season.

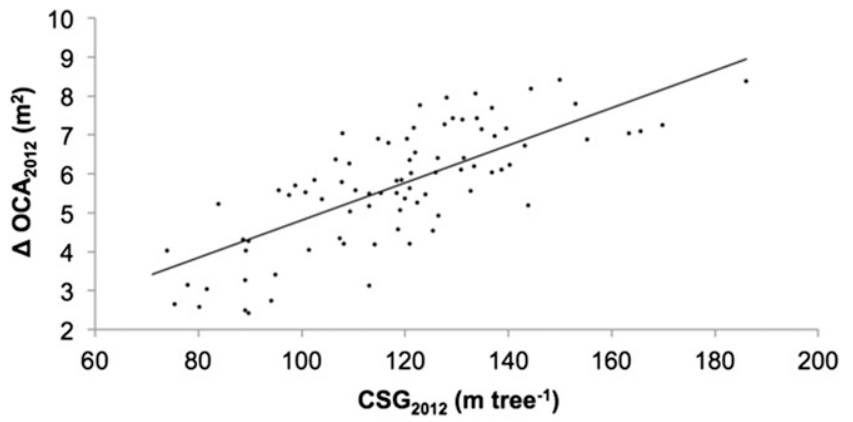

Fig. 11. Correlation between cumulative shoot growth $\left(\mathrm{CSG}_{2012}\right)$ and orthoimage canopy area increase $\left(\Delta \mathrm{OCA}_{2012}\right)$ in the 2012 season growing. Curve fitting equation: $y=0.0481 x . P$ (model) $<0.0001$. $r^{2}: 0.5737$.

management (Fig. 10). This figure shows the mean distribution of TL for the treatments before $\left(\mathrm{TL}_{\mathrm{bp}}\right)$ and after $\left(\mathrm{TL}_{\mathrm{ap}}\right)$ pruning in 2012. There were many differences between treatments before the pruning that could be attributed to treatment effects. After pruning, such differences were reduced since one of the objectives of pruning practices is orchard uniformity. It is important to note that the experimental trial was conducted in a commercial fruit orchard in which company operators performed the pruning manually. Thus, the detection of differences between treatments after pruning could be attributed to the pruning performance of each operator. Therefore, image techniques allowed us to study not only the treatment effects but also the overall pruning performance, which is valuable information for researchers and field technicians alike.

Figure 11 shows the relation between the increase in OCA $\left(\triangle \mathrm{OCA}_{2012}\right)$ and $C S G$ in $2012\left(\mathrm{CSG}_{2012}\right)$ growing season. A linear correlation was detected between these two variables $\left(y=0.0481 x ; r^{2}=0.5737\right)$, both representing the cumulative plant growth during 2012 growing season. While CSG integrated the tree growth from shoots and branches, $\triangle \mathrm{OCA}$ integrated the tree growth from leaf biomass. By analyzing both variables, we were able to get a rough idea of the total aboveground biomass produced in a single season (2012). In addition, there was a positive correlation between these two variables, so the more shoots/branches a tree generated, the more leaf biomass it was able to produce, as both GSG and $\triangle \mathrm{OCA}$ increased linearly as shown in Fig. 11.

\section{Conclusions}

The OCA (expressed in $\mathrm{m}^{2}$ ) method proved reliable to study active crop growth along the season. The OCA was closely related to TD (expressed in $\mathrm{mm}$ ) measurements, with a high degree of correlation during early growing stages. We consider these two techniques suitable to study active fruit tree growth since they are nondestructive and growth-sensitive approaches. However, although related, these methods measure different tree growth parameters.

Cumulative crop growth was determined by the VP (expressed in $\mathrm{m} /$ tree) method and was well correlated with fruit tree PW (in kg/ tree). We propose that VP is a good estimator of PW since it proved to be a reliable technique and required fewer resources than other classical techniques (i.e., PW). Furthermore, by analyzing the TL of a tree before and after pruning, we gathered information on pruning performance. Cumulative shoot growth and increase in OCA $(\triangle \mathrm{OCA})$ provided information on aboveground biomass production and were positively correlated.

Given the sensitivity to tree growth and the nondestructive nature of these image techniques, we consider them novel and highly suitable tools for research into active fruit tree growth.

\section{Literature Cited}

Abrisqueta, I., L.M. Tapia, W. Conejero, M.I Sánchez-Toribio, J.M. Abrisqueta, J. Vera, and M.C. Ruiz-Sánchez. 2010. Response of early-peach (Prunus persica L.) trees to deficit irrigation. Span. J. Agr. Res. 8(2):30-39.

Ahmed, R., P. Siqueira, S. Hensley, and K. Bergen. 2013. Uncertainty of forest biomass estimates in North temperate forests due to allometry: Implications for remote sensing. Remote Sens. 5(6):3007-3036.

Ali, H. and M.A. Anjum. 2004. Aerial growth and dry matter production of potato (Solanum tuberosum L.) cv. Desiree in relation to phosphorus application. Intl. J. Agr. Biol. 6(3):458461.

Allen, R.G., L.S. Pereira, D. Raes, and M. Smith 1998. Crop evapotranspiration. Guidelines for computing crop water requirements. FAO Irrigation and drainage paper 56, Rome, Italy.

Baker, B., D.M. Olszyk, and D. Tingey. 1996. Digital image analysis to estimate leaf area. J. Plant Physiol. 148(5):530-535.

Berner, L.T., H.D. Alexander, M.M. Loranty, P. Ganzlin, M.C. Mack, S.P. Davydov, and S.J. Goetz. 2015. Biomass allometry for alder, dwarf birch, and willow in boreal forest and tundra ecosystems of far northeastern Siberia and north-central Alaska. For. Ecol. Mgt. 337:110-118.

Bevacqua, D., M. Génard, and F. Lescourret. 2012. A simple model to predict the probability of a peach (Prunus persica L.) tree bud to develop as a long or short shoot as a consequence of winter pruning intensity and previous year growth. PLoS One 7(12): e52185.

Board, J.E., M. Kamal, and B.G. Harville. 1992. Temporal importance of greater light interception to increased yield in narrow-row soybean. Agron. J. 84(4):575-579.

Bréda, N.J.J. 2003. Ground-based measurements of leaf area index: A review of methods, instruments and current controversies. J. Expt. Bot. 54(392):2403-2417.

Bryla, D.R., E. Dickson, R. Shenk, R.S. Johnson, C.H. Crisosto, and T.J. Trout. 2005. Influence of irrigation method and scheduling on patterns of soil and tree water status and its relation to yield and fruit quality in peach. Plant Soil 40:2118-2124.

HortScience Vol. 50(12) December 2015 
Bryla, D.R., T.J. Trout, J.E. Ayars, and R.S. Johnson. 2003. Growth and production of young peach trees irrigated by furrow, microjet, surface drip, or subsurface drip systems. HortScience 38:1112-1116.

Campillo, C., M.I. García, C. Daza, and M.H. Prieto. 2011. Study of a non-destructive method for estimating the leaf area index in vegetable crops using digital images. HortScience 45:1459-1463.

Campillo, C., M.H. Prieto, C. Daza, M.J. Monino, and M.I. Garcia. 2008. Using digital images to characterize canopy coverage and light interception in a processing tomato crop. HortScience 43:1780-1786.

Diebolt, K.S. and K.W. Mudge. 1988. Use of a video-imaging system for estimating leaf surface area of Pinus sylvestris seedlings. Can. J. For. Res. 18(3):377-380.

Durkaya, B., A. Durkaya, E. Makineci, and M. Ülküdür. 2013. Estimation of above-ground biomass and sequestered carbon of Taurus Cedar (Cedrus libani L.) in Antalya, Turkey. IForest. 6(5):278-284.

Evans, G.C. 1972. The quantitative analysis of plant growth. University of California Press, Berkeley, CA.

Fernández-Pacheco, D.G., D. Escarabajal-Henarejos, A.J. Ruiz-Canales, J. Conesa, and J.M. MolinaMartínez. 2014. A digital image-processingbased method for determining the crop coefficient of lettuce crops in the southeast of Spain. Biosystems Eng. 117:23-34.

Gallego, F.J., N. Kussul, S. Skakun, O. Kravchenko, A. Shelestov, and O. Kussul. 2014. Efficiency assessment of using satellite data for crop area estimation in Ukraine. Intl. J. Appl. Earth Obs. 29:22-30.

Goetz, S.J., S.D. Prince, S.N. Goward, M.M. Thawley, and J. Small. 1999. Satellite remote sensing of primary production: An improved production efficiency modeling approach. Ecol. Modell. 122(3):239-255.
Jonckheere, I., S. Fleck, K. Nackaerts, B. Muys, P. Coppin, M. Weiss, and F. Baret. 2004 Review of methods for in situ leaf area index determination: Part I. Theories, sensors and hemispherical photography. Agr. For. Meteorol. 121(1-2):19-35.

Kvet, J. and J.K. Marshall. 1971. Assessment of leaf area and other assimilating plant surfaces, p. 517-555. In: Z. Sestak, J. Catsky, and G. Jarvis (eds.). Plant photosynthetic production. Manual of methods. Dr. W. Junk, The Hague, Netherlands.

Le Toan, T., S. Quegan, M.W.J. Davidson, H. Balzter, P. Paillou, K. Papathanassiou, S. Plummer, F. Rocca, S. Saatchi, H. Shugart, and L. Ulander. 2011. The BIOMASS mission: Mapping global forest biomass to better understand the terrestrial carbon cycle. Remote Sens. Environ. 115:2850-2860.

Li, X., H. Zhao, Y. Liu, H. Jiang, and Y. Bian. 2014. Laser scanning based three dimensional measurement of vegetation canopy structure. Opt. Lasers Eng. 54:152-158.

Lindsey, P.A. and N.L. Bassuk. 1992. A nondestructive image analysis technique for estimating whole-tree leaf area. HortTechnology 2:66-70.

Loomis, R.S., W.A. Williams, and W.G. Duncan. 1967. Community architecture and the productivity of terrestrial plant communities, p. 291-308. In: A. San Pietro, F. A. Greer, and T. J. Army (eds.), Harvesting the sun. Photosynthesis in plant life. Academic Press, New York.

Monteith, J.L. 1969. Light interception and radiative exchange in crop stands. Paper presented at the Proceedings of Physiological Aspects of Crop Yield. Proceedings of the ASA and CSSA, Lincoln, NE.

Monteith, J.L. 1977. Climate and efficiency of crop production in Britain. Philos. T. Roy. Soc. B. 281(980):277-294.

Mulla, D.J. 2013. Twenty five years of remote sensing in precision agriculture: Key advances and remaining knowledge gaps. Biosystems Eng. 114(4):358-371.
Palacín, J., T. Pallejà, and M. Tresanchez. R. Sanz, J. Llorens, M. Ribes-Dasi, J. Masip, J. Arno, A. Escolà, and J.R. Rosell. 2007. Real-time tree-foliage surface estimation using a ground laser scanner. IEEE T. Instrum. Meas. 56 (4):1377-1383.

Pallejà, T., M. Tresanchez, M. Teixido, R. Sanz, J.R. Rosell, and J. Palacín. 2010. Sensitivity of tree volume measurement to trajectory errors from a terrestrial LIDAR scanner. Agr. For. Meteorol. 150(11):1420-1427.

Pforte, F., J. Selbeck, and O. Hensel. 2012. Comparison of two different measurement techniques for automated determination of plum tree canopy cover. BioSyst. Eng. 113(4):325333.

Rico-García, E., F. Hernández-Hernández, G.M Soto-Zarazúa, and G. Herrera-Ruiz. 2009. Two new methods for the estimation of leaf area using digital photography. Intl. J. Agr. Biol. 11(4):397-400

Ross, J. 1981. The radiation regime and architecture of plant stands. Tasks Veg. Sci., Ser. Vol. 3. Springer Netherlands, Dordrecht, the Netherlands.

Serdar, Ü. and H. Demirsoy. 2006. Non-destructive leaf area estimation in chestnut. Sci. Hort. 108:227-230

Smith, F.W., D.A. Sampson, and J.N. Long. 1991. Notes: Comparison of leaf area index estimates from tree allometrics and measured light interception. For. Sci. 37(6):1682-1688.

van Wijk, M.T. and M. Williams. 2005. Optical instruments for measuring leaf area index in low vegetation: Application in Arctic ecosystems. Ecol. Appl. 15(4):1462-1470.

Wei, J. and M. Salyani. 2005. Development of a laser scanner for measuring tree canopy characteristics Phase 2. Foliage density measurement. T. ASAE. 48(4):1595-1601.

Willaume, M., P.É. Lauri, and H. Sinoquet. 2004. Light interception in apple trees influenced by canopy architecture manipulation. Trees (Berl.) 18(6):705-713. 